\title{
¿Delito o desgracia? Juan de Hevia Bolaños y la calificación de la quiebra*
}

\section{ANDREA LANDI ${ }^{* *}$}

RESUMEN. El ensayo examina la figura de la quiebra en la reflexión de Hevia Bolaños, autor de referencia en materia de difusión en el Nuevo Mundo del ius mercatorum elaborado en Europa. De este análisis se deriva un estudio de la experiencia del derecho común, donde hay una valoración profundamente antijurídica de la quiebra, lo que ha dado lugar en la edad moderna a individualizar varias tipologías de deudores quebrados (y por tanto de quiebras), admitiendo así también la quiebra inculpable. De esta diversificación Hevia es un testigo puntual, cuyas reflexiones se retoman, más o menos de manera consciente, también de las legislaciones comerciales españolas y, especialmente, de las mexicanas del siglo XIX.

Palabras Clave: quiebra, derecho comercial, código de comercio, derecho común romano-canónico, ius mercatorum.

Fecha de recepción: 28 de mayo de 2020. Fecha de aceptación: 28 de agosto de 2020.

Para citar el artículo: LANDI, A., “¿Delito o desgracia? Juan de Hevia Bolaños y la calificación de la quiebra", Revista de Derecho Privado, Universidad Externado de Colombia, n. ${ }^{\circ} 40$, enero-junio 2021, 13-42, DOI: https://doi.org/10.18601/01234366.n40.02.

Trad. del italiano: Deisy Villalobos.

** Università di Pisa, Pisa, Italia; profesor asociado. Doctor en Storia del diritto, delle istituzioni e della cultura giuridica medievale, moderna e contemporanea, Università degli Studi di Genova, Genova, Italia. Contacto: andrea.landi@unipi.it Orcid: 0000-0002-3826-9481. 


\title{
Misdeed or Misfortune? Juan de Hevia Bolaños and the Qualification of Bankruptcy
}

\begin{abstract}
This essay examines the figure of the bankrupt debtor in the conception of Hevia Bolaños, which is considered the main vehicle of diffusion in the New World of the ius mercatorum elaborated in Europe. As a result of this analysis is found a sort of long lasting experience of the ius commune, which setting off from a profoundly unlawful valuation of bankrupt, had come to identify in modern times various types of bankrupt debtors (and therefore of bankruptcies), which has led to also admitting a faultless bankruptcy. Hevia is a punctual witness of this diversification, which is taken as a benchmark, more or less consciously, by the Spanish commercial legislations and especially Mexican legislation of the 19th century.
\end{abstract}

Keywords: bankruptcy, Commercial Law, Commercial Code, Ius Commune, Roman-Canon Law, Ius Mercatorum.

Sumario. I. Juan de Hevia Bolaños: un ius mercatorum para las Indias Occidentales. II. El quebrado según Hevia Bolaños. III. La quiebra entre codificación y derecho novohispano: del antiguo derecho indiano al código de comercio mexicano de 1854. Conclusiones. Referencias.

\section{Juan de Hevia Bolaños: un ius mercatorum para las Indias Occidentales}

Si, con razón, Benvenuto Stracca puede ser considerado el primero en sistematizar la materia comercial en la Europa del siglo $\mathrm{XvI}^{1}$, en el lado opuesto del Atlántico este reconocimiento se debe atribuir a Juan de Hevia Bolaños (1570 ca.-1623) $)^{2}$ por dos obras que se pueden definir cómo auténticos best sellers jurídicos, destinados a reco-

1 Con su De mercatura seu de mercatore tractatus, aparecido en Venecia en 1553, reimpreso varias veces también en el siglo siguiente e insertado en la colección enciclopédica recopilada en los Tractatus Universi Iuris de ZileTti (vi/1, Venetiis, 1584, fo. 284rb-303ra). Para una valoración de la obra y de la figura de Stracca, además de las contribuciones destacadas de Franchi, L., Benvenuto Stracca, giureconsulto anconitano del secolo XVI: note bio-bibliografiche, Roma 1988 y LATTES, A., "Stracca giureconsulto", Rivista di diritto commerciale, vII, 1909, 624 ss., véanse ahora, entre otros, Vito Piergiovanni, en Dizionario biografico dei giuristi italiani (= DBGi), Birocchi, I., Cortese, E., Mattone, A. y Miletti, M. N. (dirs.), t. i, Bologna, Il Mulino, 2013, 1920-1922 у Benvenuto Straccha. Ex Antiquitate renascor, Atti del Convegno, Ancona, 22 de febrero de 2013, Ancona, Gabbiano, 2014.

2 Detalles biográficos en García SÁnchez, J., "Juan de Hevia Bolaño: asturiano, autor de la 'Curia Filípica' y del 'Laberinto de mercaderes' (anotaciones a una cuestión histórico-jurídica enigmática), Boletín del Real Instituto de Estudios Asturianos, año XLIx (1995), 506-543 y actualmente también en Garrido Arredondo, J., s.v. "Hevia Bolaño [o Bolaños], Juan de", Diccionario crítico de juristas españoles, portugueses y latinoamericanos (hispánicos, brasileños, quebequenses y restantes francófonos), I, Zaragoza-Barcelona, Universidad de Murcia et al., 2005, 415. 
rrer, con una serie impresionante de ediciones, todo el Ancien Régime hasta el siglo XIX de las codificaciones: la Curia Filípica, aparecida en Lima en 1603 para ofrecer un tratamiento profundo del derecho procesal vigente en los dominios españoles, y el Labyrintho de comercio terrestre y naval, publicado por primera vez, también en Lima, en 1617 y dedicado a la exposición de todo aquello que se refería a las mercaderías, desde los contratos hasta las Instituciones, al punto que aparecía "provechoso para Mercaderes, Negociadores, Navegantes, y sus Consulados, Ministros de los Iuyzios, professores de Derechos, y otras personas" 3 .

Como afirmó un autorizado estudioso del derecho comercial, "el Laberinto constituye el primer tratado español de Derecho mercantil, con el que se afirma su autonomía científica"4; de hecho, por primera vez, se ve un tratamiento unitario y sistemático de la materia, inexistente hasta entonces, excepción hecha del de Stracca; y por el hecho de estar escrito en castellano, como por su brevedad y claridad, fue bastante aceptado por los operadores del derecho y, por lo tanto, muy solicitado por el mercado editorial ${ }^{5}$. Sin embargo, es necesario dejar claro desde ahora que el Labyrintho no fue una obra excepcional, en el sentido de que se separara, con sus propias características, de las otras obras de literatura jurídica indiana 6 .

Como se sabe, Hevia Bolaños y su obra pertenecen a aquel periodo particularmente prolífico para el derecho indiano de la primera mitad del siglo XVII, "una

3 Hevia Bolaños, J. DE, Labyrintho de comercio terrestre y naval, En Lima, Por Francisco del Canto, natural de Medina del Campo, 1617. Una reseña de las ediciones (más de treinta) del Labyrintho y de la Curia (desde 1644 impresos conjuntamente), en Lohmann Villena, G., "En torno de Juan de Hevia Bolaño. La incógnita de su personalidad y los enigmas de sus libros", Anuario de Historia del Derecho Español (= AHDE), XXXI, 1961, 159-161; en Scherner, K. O., "Die Wissenschaft des Handelsrechts", en CoING, H. (ed.), Handbuch der Quellen und Literatur der neuren europäischen Privatrechtsgeschichte, iI/1, München, C.H. Beck, 1977, 864, y en CASAGRAnde, A., "Curia Philippica (Philippic Court) 1603”, en Dauchy, S., Martyn, G., Musson, A., Pihlajamäki, H. y Wijffels, A. (eds.), The Formation and Transmission of Western Legal Culture. 150 Books that Made the Law in the Age of Printing, Cham, Springer, 2016, 156.

4 Muñoz Planas, J. M., "Defensa y elogio de Juan de Hevia Bolaños: primer mercantilista español", Revista de Derecho Mercantil, n. . 241, 2001, 1187. Por lo mismo, en opinión de Muñoz, la obra de Hevia "marca un antes y un después" (p. 1185).

5 Las virtudes de esta obra fueron resumidas ya por Juan de Solórzano y Pereira, en la aprovacion, dada en Lima el 20 de julio de 1616 (sin numeración de las páginas), en la cual no se encontraba nada digno de censura, salvo el título, "porque Laberinto significa cosa intricada y confusa. Y lo que tiene mejor es la claridad y la distincion, con que entra y sale en materias tan graves y dificultosas como las que recoje, tocando, y resolviendo en ellas los puntos mas sustanciales y praticables, y haziendo tan manual y suave la inteligencia de los contratos como hizo antes de los juyzios en el otro libro que compuso llamado Curia Philippica, que en todas partes ha sido bien recibido".

6 Tau Anzoátegui, V., El jurista en el Nuevo Mundo. Pensamiento. Doctrina. Mentalidad, Frankfurt am Main, Max Planck Institut for European Legal History, 2016, 133 y 141, incluye la Curia Filipica, junto a la Política indiana de Solórzano y la Política para corregidores de Castillo de Bobadilla entre aquellos "con auctoritas, fijadores de la jurisprudencia castellano-indiana". Sobre esta literatura “típicamente indiana”, cfr. MALAGÓN-BARCELó, J., La literatura jurídica española del Siglo de Oro en la Nueva España, México, unAm, 1959, 22, 38, 45-46 y Bravo LiRA, B., "El derecho indiano después de la independencia en América española: legislación y doctrina jurídica”, Historia, 19, 1984, 14. 
época eminentemente creativa, en la que la literatura jurídica indiana alcanza gran vuelo"7 y, al interpretar las necesidades de la práctica, elabora las obras que responden plenamente a estos menesteres. Si es indudable la existencia de algunos rasgos distintivos de las obras jurídicas indianas de este periodo -la adaptación del razonamiento jurídico a los esquemas del ius commune, el interés por la práctica, la idea de una justicia que debe escapar de las abstracciones (ars boni et aequi) y la utilización del método casuístico ${ }^{8}$-, es igualmente cierto que estas características se encuentran íntegramente en las obras de Hevia Bolaños, quien, en esto, no se aleja de los autores de su tiempo: respecto de la Curia como del Labyrintho podemos decir que estamos ante trabajos importantes, pero no extraordinarios en cuanto al contenido 9 .

Esta constatación permitió a algunos historiadores del derecho sembrar algunas dudas sobre la paternidad de estas dos obras que, precisamente en consideración de su presunta excepcionalidad en el contexto jurídico barroco español, no habrían podido ser atribuidas a un personaje de dudosa cuna y carrera como Hevia Bolaños - de quien se sabe únicamente que fue originario de Oviedo y que trabajó en Perú ${ }^{10}$, sino que debían ser atribuidas a juristas de mayor estatura ${ }^{11}$, incluso a Juan de Solórzano y Pereira, el más importante jurista indiano ${ }^{12}$.

7 Así Bravo LiRa, B., "El derecho común en ultramar. Autores y obras jurídicas de la época del Barroco en Hispanoamérica”, Ius Commune. Zeitschrift für Europäische Rechtsgeschichte, xv, 1988, 5.

8 Los abordó convincentemente Bravo LiRA, El derecho común en ultramar, cit., 26-33. Sobre el punto, en el mismo sentido, también LuQue Talaván, M., Un universo de opiniones. La literatura jurídica indiana, Madrid, Consejo Superior de Investigaciones Científicas, 2003, 212-215.

9 Casagrande, s.v. "Curia Philippica (Philippic Court) 1603", cit., 158, habló de la Curia -pero el juicio puede extenderse también al Labyrintho- como "an important but not extraordinary work". Incluso Petit, C., Historia del derecho mercantil, Madrid, Marcial Pons, 2016, 98, define la Curia "obra mediocre aunque difundidísima".

10 "Curioso personaje de origen asturiano" lo define Dougnac Rodríguez, precisando que sus estudios jurídicos no se conocen y que tuvo "oscuros puestos en Quito y Lima", aunque el historiador chileno no duda de la autoría de las dos obras (cfr. Dougnac Rodríguez, A., Manual de historia del derecho indiano, 2. ' ed., México, unam, 1998, 194); cfr. también García SÁnchez, J., "La 'laesio enormis': del rescripto de Diocleciano (C.4.44.2) en el Codigo de Comercio hispano de 1829, pasando por Hevia Bolaño", Revue Internationale des droits de l'Antiquité, XLVIII, 2001, 109-111.

11 Esta, en síntesis, la tesis del historiador peruano Guillermo Lohmann, ya sostenida en LoHMANN Villena, G., En torno de Juan de Hevia Bolaño, cit., 121-161 y reiterada en ID., "Juan de Hevia Bolaño: nuevos datos y nuevas disquisiciones", Histórica, XVIII, n. ' 2, 1994, 317-333.

12 Sobre el cual nos permitimos reenviar a LANDI, A., "“Unum et idem Regnum'. L'unione del Nuovo Mondo alla corona di Castiglia nella riflessione di Juan de Solórzano y Pereira”, Quaderni fiorentini per la storia del pensiero giuridico moderno, XLI, 2012, 152-154, ahora en ID., Storia giuridica per futuri giuristi. Temi e questioni, Torino, Giappichelli, 2015, 114-116. Sobre el valor de Solórzano, entre otros, cfr. BRAVO LIRA, B., "El derecho indiano y sus raíces europeas: derecho común y propio de Castilla", AHDE, LVIII, 1988, 38, que lo define "uno de los mayores juristas de su época y, sin disputa, el primero entre los indianos". 
No obstante los autorizados avales dados a esta dudosa tesis en el pasado ${ }^{13}$, hoy parece pacífico, de hecho, que las dos obras pueden ser atribuidas a este jurista asturiano $^{14}$.

El Labyrintho es la obra que más nos interesa en esta ocasión, porque nos permite ver cómo se percibió la figura del quebrado en el derecho indiano: de hecho, con esta obra de Hevia Bolaños, donde el derecho mercantil se trató de manera unitaria a propósito (el derecho marítimo junto al terrestre) $)^{15}$, nos encontramos frente a "un perfecto ejemplo de confluencia entre la doctrina romanista bajomedieval, el 'mos italicus' tardío, la obra de Stracca (sin duda el autor más veces citado) y su propia experiencia"16.

Es decir, una proyección ultramar del ius mercatorum europeo.

\section{El quebrado según Hevia Bolaños}

El capítulo 11 del libro II del Labyrinto ${ }^{17}$ inicia con una definición de quebrados que Hevia extrae de ejemplos directamente identificados en las leyes de la Nueva

13 Entre otros, García-Gallo, A., "La ciencia jurídica en la formación del derecho hispanoamericano en los siglos XVI al XVIII", AHDE, XLIV, 1974, 197, nota 136.

14 Cfr. Coronas, S. M., "Hevia Bolaños y la "Curia Philippica", AHDE, LXXVII, 2007, 77-93, según el cual el debate sobre la paternidad de estas obras "puede darse por resuelto a favor de Hevia una vez despejadas ciertas dudas sobre su personalidad y la naturaleza de su obra" (p. 77). En particular las investigaciones de García Sánchez dieron cuenta de una sólida formación humanista de Hevia y de su relación con el mundo de los prácticos y de los comerciantes. Así que, aunque nunca se graduó en derecho, podía definirse como un experto en la materia a pleno título (cfr. GARCía SÁNCHEZ, J., Juan de Hevia Bolaño: asturiano, autor de la 'Curia Filípica' y del 'Laberinto de mercaderes', cit., 536-543). Entre líneas, estas consideraciones se advierten también en el siempre útil ANTONIO, N., Bibliotheca Hispana nova sive Hispanorum scriptorum qui ab anno 1500 ad 1684 floruere notitia, I, Matriti, Apud Joachimum de Ibarra typographum regium, 1783 (reimp. anastática, Torino, Bottega d'Erasmo, 1963), 710.

15 Lo han destacado del Vas Mingo, M. M. y Luque Talaván, M., "La usura en la literatura jurídica indiana de los siglos XVI-XVII: la propuesta de Juan de Hevia Bolaños y sus fuentes", en Morales PAdRón, F. (coord.), XIII Coloquio de Historia Canario-Americana. VIII Congreso Internacional de Historia de América (1998), Cabildo de Gran Canaria, 2000, 1089.

16 Así Tomás y Valiente, F., Manual de historia del derecho español, 4. a ed., Madrid, Tecnos, 2013, 364. A Stracca como modelo parece hacer mención también el mismo Hevia Bolaños, Labyrintho de comercio terrestre y naval, cit, en la presentación de la obra al lector, donde se afirma no haber visto hasta entonces nada escrito "ex professo y junto" en materia comercial, "sino por uno, Benvenuto Straccha Anconitano (aunque docta cortamente)".

17 Obsérvese la versión en latín de la edición del Labyrintho (Labyrinthus commercii terrestris et navalis e patrio hispano idiomate in latinum versus, Florentiae, Typis Regis Petrum Antonium Brigonci, 1702), respecto de las ediciones en español: en estas, los dos libros dedicados al comercio terrestre se conforman de quince capítulos cada uno, con numeración progresiva que comienza de nuevo para cada libro. Mientras que en la edición en latín los capítulos tienen una numeración continua entre el primer y el segundo libro, de manera que este capítulo 11 Falidos del libro 2 se convierte en el caput XXVI Decoctores del libro 2 (pp. 156-164). 
Recopilación ${ }^{18}$ y de aquellos extraídos, por vía de interpretación, del Corpus iuris civilis. De hecho, a la consideración de que "falidos son los mercaderes, Cambios, y bancos, o sus factores, que faltan, o quiebran en sus pagas, creditos, o contrataciones y negocios"19, Hevia hace seguir una lista de todas las tipologías, con las relativas indicaciones de las leyes reales que se ocupan de ellas.

En primer lugar, están aquellos que huyen con activos o libros contables ${ }^{20}$; luego, aquellos "que se alçan con los bienes o libros", pero no huyen ${ }^{21}$; después, aquellos que ocultan los bienes o escrituras, sin esconderse a sí mismos o huir ${ }^{22}$; luego, aquellos que huyen o se esconden, resguardándose en algún lugar sagrado, aun cuando no hacen desaparecer bienes y libros ${ }^{23}$; finalmente, aquellos que no cumplen sus obligaciones "por falta de bienes", aunque no escondan tales bienes o a sí mismos ${ }^{24}$.

A estos supuestos, con directo respaldo en el derecho real, Hevia agrega otros tres, que podían ser identificados con fundamento en el derecho romano.

La primera de estas se refería a los deudores que no podían cumplir sus deudas: a propósito de ellos, él reenvía a un pasaje de las Instituciones justinianeas y a otro del Digesto ${ }^{25}$, donde se hablaba del deudor "solvendo", y de aquel que no podía hacer frente a sus deudas.

En particular, si la $l$. Solvendo del Digesto se limitaba a ofrecer una simple definición de la primera clase de deudor ${ }^{26}$, en el $\S$ Fulloni de las Instituciones se discutía sobre el ejercicio de la actio furti por parte de un lavandero o de un sastre, a quien le fueron robadas las cosas a él entregadas en virtud de su trabajo ${ }^{27}$; la solución que se daba tenía en cuenta el principio según el cual "actio furti competit illi, cuius interest

18 De la Nueva Recopilación de 1567 se consultó la edición Madrid, I, En la Imprenta de Juan de Zuñiga, 1745.

19 Hevia Bolaños, Labyrintho de comercio terrestre y naval, cit., 443-444.

20 N.Recop., 5.19.1.

21 N.Recop., 5.19.2.

22 N.Recop., 5.19.3.

23 N. Recop., 5.19.6.

24 N.Recop., 5.19.5.

25 Respectivamente, Inst., De obligationibus, § Fulloni (Inst. 4.1.15) y la l. Solvendo ff. De verborum significatione (D. 50.16.114).

26 La l. Solvendo ff. De verborum significatione (D. 50.16.114): "Solvendo, esse nemo intelligitur, nisi qui solidum potest solvere"; obsérvese que ya la glosa de referencia reenviaba, como locus parallelus, al § Fulloni. Para el Corpus Iuris civilis se hará referencia a la edición Lugduni, Apud Hugonem en Porta, 1558-1560.

27 Inst., De obligationibus, § Fulloni (Inst. 4.1.15): "Fulloni vero et sarcinatori non aliter furti actionem competere placuit, quam si solvendo fuerint: hoc est, si domino rei aestimationem solvere possint. Nam si solvendo non sint: tunc quia ab eis suum dominus consequi non possit, ipsi domino furti competit actio: quia hoc casu ipsius interest rem salvam esse. Idem est et si in parte solvendo fuerit fullo, aut sarcinator". 
furtum factum non esse"28; así que, si el lavandero es solvente, será él quien tendrá interés en ejercitar la actio para recuperar los bienes, mientras que si no lo es, será el dominus rei quien tendrá este interés.

El segundo ejemplo se refiere a aquellos que, no pudiendo pagar illico et immediate, solicitan el remedio de la moratoria o de la liberación de sus deudas. Esta clase de deudores fueron tenidos en consideración ya desde el derecho romano ${ }^{29}$, aunque Hevia remita, para su identificación, únicamente al derecho real ${ }^{30}$.

Y, por último, estaban los que, en virtud de las deudas contraídas, padecen la ejecución solicitada por los acreedores o entregan sus propios bienes; deudores que, al fin de cuentas, se presume que no están en capacidad de hacer frente a sus obligaciones, precisamente porque lo hacen con estas modalidades extraordinarias ${ }^{31}$.

Era demasiado claro que todos estos supuestos no podían ser considerados en el mismo sentido por el legislador (y también por la conciencia social, que estaba llamado a interpretar).

Es decir, había quebrados de quebrados: la rígida equiparación "fallitus ergo fraudator", ya entrada en crisis en la reflexión de Stracca $^{32}$, perdía posteriormente su razón de ser en el exterior por Hevia Bolaños.

De aquí, entonces, la necesidad de distinguir, de acuerdo con el jurista asturiano, tres categorías de deudores quebrados.

28 Como aparece sintetizado en un titular editorial de la edición del siglo Xvi que hemos consultado, que relata la opinión di Angelo Gambiglioni d'Arezzo.

29 Se trataba de aquellos que recurrían a las llamadas Induciae quinquennales (sobre las cuales cfr. C. 7.71.8); un instituto considerado por muchos comercialistas como el origen de las elaboraciones medievales sobre los acuerdos concursales, aunque ya Rocco, A., Il concordato nel fallimento $e$ prima del fallimento, Torino, Fratelli Bocca, 1902, p. 35, anotaba que, "tratándose de un beneficio, cuya concesión estaba reservada al emperador, se [estaba] más en el campo de la moratoria que en el del concordato".

30 N. Recop., 5.19.6-7.

31 Y, en este sentido, creemos que se puede entender la remisión de Hevia a un comentario bartoliano, donde el Maestro del siglo xiv, al terminar la exposición de un fragmento dedicado a varias problemáticas sobre la gestión de la tutela por parte de una pluralidad de tutores y a la prodigalidad, observaba, con la acostumbrada agudeza, que "quando bona alicuius venduntur ad petitionem creditoris, praesumptio est, quod non sit solvendo"; cfr. BARTolo DA SASSOFERRATo, En l. Tres tutores ff. De admin. et peri. tut. et cura. (D. 26.7 .55 [56], en ID., Commentaria, III, In primam Infortiati partem, Venetiis (L.A. Giunti), 1602, fo. 58rb. Sin embargo, no falta el reenvío, por parte de Hevia, también al derecho real, conformado por dos leyes de las Partidas (5.15.7 y 9). Para esta recopilación normativa, de Alfonso x El Sabio, en este estudio se hizo referencia a Las siete Partidas glosadas por el Licenciado Gregorio López, En Salamanca, Por Andrea de Portonariis, 1555 (ed. facsimilar, Madrid, Boletín Oficial del Estado, 1974).

32 Stracca, B., Tractatus de conturbatoribus sive decoctoribus, en De mercatura decisiones et tractatus varii, Lugduni. P. Landry, 1610 (reimp. anastática, Torino, Bottega d'Erasmo, 1971), pars 2, 474, n. 1. Para esta reflexión consúltese ahora LaNDi, A., 'Proiezioni 'ultramar' del 'ius mercatorum' europeo. La definizione di 'fallito' nel 'Labyrintho de commercio' di Juan de Hevia Bolaños”, en Petrucci, A. (coord.), I rapporti fiduciari: temi e problemi, en proceso de impresión por Giappichelli de Turín, en el cual se propusieron de nuevo, en relación con el contexto italiano, partes del presente artículo. 


\section{A. La primera categoría de deudores en quiebra}

Son aquellos que se quiebran "fortunae vitio", de los cuales hablaban Stracca y Juan de Matienzo, resaltando que no pueden ser sancionados penalmente. Stracca, en este sentido, había destacado que debían ser considerados "inter viles homines" y, citando una Satira 33 , había concluido que se estaba ante un "genus hominum miserabile"34; mientras que Matienzo, con la mirada puesta principalmente en la legislación real, afirmó que "in decoctore autem seu fallito lex nostra non procedit, si fraudem nullam commisit [...] ut puta qui nihil occultat, sed vere solvendo non est"35.

El "momento de validez" de esta solución lo encontró Hevia en algunos pasajes de la compilación justinianea, establecidos en materias aparentemente muy distantes de aquellas que estamos tratando y sin embargo usadas como "materiales de construcción" para el nuevo edificio del procedimiento de quiebra.

En primer lugar, la referencia es a la l. Cum solito C. Qui bonis cedere possunt (C. 7.71.8), donde el emperador Justiniano fijaba el procedimiento para que, a elección de los acreedores, se acordara en beneficio del deudor la bonorum cessio o el aplazamiento del pago: un procedimiento que, por tanto, con independencia de sus articulaciones, presuponía una valoración no negativa del deudor y que, como tal, llevaba a excluir la relevancia penal de su insolvencia.

Pero es, sobre todo, en la $l$. Divus ff. De officio Praesidis (D. 1.18.14) que se reitera la no relevancia penal del supuesto analizado: en este texto se recogía el contenido de un rescripto en el cual, frente a una persona insana de mente, ya internada por esta causa y confiada a tutores y, en fin, sospechosa sin fundamento de haber matado a su madre, el emperador Marco Aurelio y Cómodo habían considerado no tener que infligir a esta persona otra pena, teniendo en cuenta el hecho de que aquel ya había sido castigado suficientemente por su misma locura (“cum satis furore ipso puniatur"); y la glosa se apresuró a extraer el principio según el cual "non debet addi afflictio afflicto" (gl. Cum satis in l. Divus, cit.), recogido ${ }^{36}$ por los comentaristas Jean Faure ${ }^{37}$ y Giovanni della Piazza ${ }^{38}$, con la adhesión

33 Iuvenalis, Satirae, 3.152-153: "Nil habet infelix paupertas durius in selquam quod ridiculos homines facit" (SANTORELli, B. [ed.], Milano, Mondadori, 2011, 34).

34 Stracca, B., De conturbatoribus, cit., pars 2, 474, n. 2.

35 Matienzo, J. De, Commentaria in librum quintum recollectionis legum Hispaniae, Mantuae Carpentanae, Excudebat Petrus Madrigal, 1597, gl. 1 en tit. 19, 11. 1 e 2, fo. 450rb, n. 2.

36 Es necesario advertir que aquel principio se predicó para evitar que el spoliatus, por guerras o hechos similares, pudiera ser demandado solidariamente; subsiste en virtud del principio enunciado en el texto un beneficio del deudor en este sentido.

37 JeAn FAure (FABer), In vers. Cum eo quoque (Inst., De actionibus, § fi. = Inst. 4.6 .40 invero: eum quoque), en ID., In Institutiones Commentarii, Lugduni, Excudebat Petrus Fradin, 1557, fo. 161rb.

38 Giovanni della Piazza, In vers. Cum eo quoque (Inst., De actionibus, § fi.), en ID., Super quatuor Institutionum lib., s. d., 1539, fo. 108 va-b, n. 10; el razonamiento del jurista boloñés, basado en la bonorum cessio, llega a la conclusión de que "post liquidationem autem et cessionem factam debitor pro bonis et obligationibus prioribus non potest effectualiter agere vel conveniri". 
del reconocido Giason del Maino ${ }^{39}$, para llegar al mismo Hevia Bolaños ${ }^{40}$ y luego a Juan de Solórzano ${ }^{41}$.

En fin, la referencia a la l. Debitores C. Ex quibus causis infamia irrogetur (C. 2.11[12].11), que excluía la imposición de la infamia al deudor que ha recurrido a la bonorum cessio para satisfacer sus créditos, pretendía equiparar definitivamente la posición del deudor insolvente en ambas situaciones -quiebra y cesión de los bienes- que también, desde el punto de vista del procedimiento, seguían siendo dis$\operatorname{tintas}^{42}$.

\section{B. La segunda categoría de deudores quebrados}

Son aquellos que se fugan con los bienes o con los registros contables, o que los ocultan, aunque no se escondan ellos mismos; sujetos que Stracca había mencionado, recordando, sin embargo, que ya Baldo había advertido la necesidad de precisar puntualmente el concepto de fuga, con el propósito de identificar el presupuesto objetivo de la quiebra y de la consiguiente subsistencia del maleficium; tal fuga se podía reconocer solo si se acompañaba de la sustracción de los bienes y de los libros contables, porque si se basaba solamente en la partida precipitada del deudor, la misma habría configurado una mera latitatio, que por sí misma no era idónea para fundamentar una declaración de quiebra ${ }^{43}$.

39 Giasone del Maino, Additio vers. Cum eo quoque in $\S$ fi. (Inst. 4.6.40), en ID., De actionibus titulus Institutionum, Francofurti ad Moenum, 1581, p. 450, n. 7; cuyo registrador, el sardo Antonio Angelo Carcassona ( $†$ ac. 1586), después de haber mencionado los comentarios citados que habían adherido a esta postura, lo consideraba además conforme al derecho "etiam pietati consentaneum" (CARCASsona, A. A., Additiones a Giasone del Maino, De actionibus, cit., p. 453, lit. d).

40 Hevia Bolaños, J. De, Curia Philipica, i, Madrid, Por Ramon Ruiz, en la Imprenta de Ulloa, 1790, parte $2, \S 17,146$, n. 29: "No pueden ser presos por deuda los que, no por su culpa, ni vicio, sino por ocasion infortuna de guerra, ó incendio, naufragio, y otros casos semejantes de mar, y tierra, perdieron sus bienes, por ser de los que no pueden ser convenidos en mas de lo que pueden hacer".

41 Solórzano y Pereira, J. de, Politica indiana, Amberes, Por Henrico y Cornelio Verdussen, 1703, L. 6 , cap. 14,522 , que recuerda explícitamente el privilegio para los deudores que habían perdido todo "por naufragio, ò por guerra" y el principio, aplicado por él mismo en juicio en Lima, de que "no se debe dar nueva aflicción á los afligidos".

42 Como se observó, "el instituto de la quiebra no será en nada sustitutivo de la cessio bonorum o de la datio in solutum que se mantendrán vitales y serán utilizables cada vez que los acreedores lo consideren oportuno". PeCorella, C. y Gualazzini, U., s.v. "Fallimento (premessa storica)”, Enciclopedia del diritto, XVI, Milano, Giuffrè, 1967, 224. De otro lado, es bastante evidente la diferencia entre cessio bonorum y quiebra, dado que aquella es "un acto negocial que encuentra en la voluntad del cedens su única fuente", mientras que en la quiebra "todo desciende de los poderes de los órganos encargados, y que desempeñen su función, no ya como sustitutos -incluso ex lege- del quebrado, sino como sujetos perfectamente autónomos, destinados a la tutela del interés de los acreedores elevado a interés público por voluntad de los legisladores": SANTARELLi, U., Per la storia del fallimento nelle legislazioni italiane dell'età intermedia, Padova, Cedam, 1964, 3-4.

43 Stracca, De conturbatoribus, cit., secunda pars ultimae partis, 505, nn. 6-7. En este sentido también Giovanni Battista CaCCIAlupi, "De debitore suspecto et fugitivo", en Tractatus universi iuris, III/2, Venetiis 1584, qu. 1, fo. 148va, n. 5; en términos análogos, también con referencia a las leyes de la Nueva Recopilación, MATIENZO, J. DE, Commentaria en librum quintum recollectionis legum 
A esta categoría de deudores quebrados pertenecen también aquellos que enajenan simultáneamente sus propios bienes o los transfieren a otros, con el propósito de ocultarlos y hacerlos inexpugnables para los acreedores: un ejemplo de estos sujetos lo encuentra Hevia en un fragmento del Digesto -también este, como los mencionados antes, aparentemente lejano del derecho de quiebra- donde se trataba de un dominus que con dolo había disminuido el peculium de su siervo, en perjuicio de los acreedores; poniendo en práctica un comportamiento que, a semejanza de aquel del deudor próximo a ser declarado quebrado, buscaba disminuir los bienes destinados a la satisfacción de los acreedores ${ }^{44}$.

En fin, se encuentran en esta segunda categoría también aquellos deudores que toman cualquier cosa en mutuo, o en custodia en los seis meses precedentes a la quiebra: estas personas se presumen quebrados ("alzados"45) si no prueban lo contrario; en otros términos, según Hevia, subsiste una presunción iuris tantum de su estado de insolvencia.

Para este propósito, si la Nueva Recopilación solamente había dicho que tales sujetos debían tenerse por quebrados ${ }^{46}$, Hevia, sobre la base de una ley de las Partidas, y haciendo referencia a fuentes importantes del derecho común, puede insistir en el carácter de presunción relativa y no legal del hecho dañoso para los acreedores, ejecutado por el deudor dentro del llamado periodo sospetto.

En la partida ${ }^{47}$ se encontraba escrito que la presunción es un medio de prueba "que quiere tanto dezir, como grand sospecha que vale tanto en algunas cosas como aueriguamiento de prueva"; medio que debe usarse con cautela "por que las sospechas, muchas vegadas non aciertan con la verdad"48; mientras que en una glosa al Decretum Gratiani Hevio leía que con frecuencia, mediante las finctiones iuris, se afirmaban cosas contrarias a la verdad, para fijar una cosa cierta, de manera tal que

Hispaniae, cit., g1. 1 in tit. 19, 11. 1 e 2, fo. 450rb: "Fuga tamen sola absque asportatione bonorum sufficiens non est ad irrogandam poenam legis nostrae".

44 Se refiere a la l. Summa cum ratione ff. De peculio (D.15.1.21 [22]), cuyo casus de referencia es de poca claridad, para determinar las infinitas posibilidades que el deudor fraudulento puede realizar para dañar a sus acreedores: "Habebam servuum peculiarem: in fraudem creditorum peculiarium diminui peculium in decem, perinde est ac si decem essent in peculio. Et pluribus modis possum dolum committere, si eum donam alicui, vel obligavi, vel comsumpsi, vel surripui, et alio transtuli".

45 Sobre el término "alzado", del que se hace uso en todo el tit. 19 del Lib. 5 della N. Recop., cfr. una definición puntual en AcEVEDo, A. DE, Commentariorum iuris civilis in Hispaniae Regias constitutiones, Quintum librum Novae Recopilationis complectens, tomus tertius, Salmanticae, Excudebat Petrus Lassus, 1597, en rubr. tit. 19, fo. 371ra, entendiéndose "qui cum a pluribus bona mercantias et res alias in creditum accepit, pretio eorum non soluto, bona sua omnia, vel pecunia aliena, creditaque occultat, licet personam suam non occultet".

46 N. Recop., 5.19.7.

47 Partidas, 3.14.8. Quantas maneras son de prueva.

48 Obsérvese, solo de paso, cómo Gregorio López, en la gl. Presumcion, de referencia, luego de haber reportado la definición de tal medio de prueba dada por Giovanni Calderini, observa que según el mismo canonista "variatur, et fortificatur et debilitatur animus iudicantis ex praesumptione, prout suadebunt circumstantiae, ex quibus risultaret". 
se debía reconocer el principio de que las presunciones admiten siempre prueba en contrario, salvo que la misma ley disponga la naturaleza iuris et de iure de la presunción ${ }^{49}$.

En esto Hevio siguió, una vez más, la opinión de Stracca, quien, como se vio, no queriendo adherir al indiscriminado rigor de Baldo, admitía la posibilidad de que los deudores quebrados probaran la causa inculpable de su quiebra ${ }^{50}$.

Los deudores quebrados de esta segunda categoría son equiparados a los pubblici fures, según las disposiciones del título De los cambios, i mercaderes que se alzan de la Nueva Recopilación ${ }^{51}$ y, por lo tanto, deben ser castigados desde el punto de vista criminal con la pena de la infamia, según el derecho romano ${ }^{52}$, y con la pena de muerte, según lo establecido por una ley de las Partidas ${ }^{53}$.

Este régimen no sufre ninguna excepción ni aun en el caso de nobles o de mujeres: de hecho, si para el primer supuesto existía una específica disposición de ley del Reino que excluía todo privilegio nobiliario ${ }^{54}$, en el caso de las mujeres Hevia encontraba en un autor de gran prestigio en el derecho indiano, Juan Castillo de Bobadilla (ca. 1547-ca. 1605) ${ }^{55}$, el fundamento normativo para extender también a la "mujer tratante alçada" ("mulier negocians, quae deficiat") ${ }^{56}$ el régimen penal apenas descrito.

No se trata de una cuestión baladí, ya que implicaba extender las disposiciones penales establecidas para el mercator -es decir, para un hombre- también a una mujer, la esposa del comerciante; incluso en virtud de la consideración de las leyes sobre la quiebra como odiosae, es decir, (tendencialmente) no aplicables al margen

49 "Ego dico breviter, quod contra omnem praesumptionem admittitur probatio, nisi ius de iure alicuius non tantum praesumit, sed etiam certum quid statuit" (gl. Quod non fuit, en cap. Ferrum Distinc. 50, c. 18).

50 "Nec enim praesumptionem illius generis esse puto, quam vocant iuris, et de iure, et quae probationem in contrarium tollat, ut sensisse videtur Baldus adeo, ut ex ea damnari decoctor possit" (STRACCA, B., De conturbatoribus, cit., pars 4, 484, n. 7).

51 N. Recop., 5.19.1-7.

52 En la l. Praetoria verba ff. De iis qui notantur infamia (D. 3.2.1), que comprendía entre los sujetos a declarar infames también aquellos que hubieran sido condenados "furti, vi bonorum raptorum"; el casus relativo, al influir la disposición romana en la experiencia del bajo medioevo, incluye el hurto y la rapiña entre los casos de infamia "per sententiam"; cfr. Migliorino, F., Fama e infamia. Problemi della società medievale nel pensiero giuridico nei secoli XII e XIII, Catania, Giannotta, 1985, 118-120.

53 Partidas, 7.14.18 Que pena merescen los furtadores, e los robadores.

54 N.Recop., 5.19.4, según la cual ningún comerciante que quiebre puede "gozar, ni goce del privilegio de la hidalguia, para escusarse de la pena del dicho delito, ni para otro caso, ni cosa alguna".

55 Su obra Politica para corregidores de 1597 fue justamente considerada como "papel de guía de gobernantes y jueces en España e Indias durante los siglos XVII y xVIII" (así TAU AnzoÁtegui, V., El jurista en el Nuevo Mundo, Pensamiento. Doctrina. Mentalidad, cit., 117; para agregar también su juicio halagüeño en 141).

56 Hevia Bolaños, J. DE, Labyrintho de comercio, cit., 447, n. 8, con la traducción en latín de la edición de Florencia, 158, n. 8. 
de los casos contemplados ${ }^{57}$, así que para las mujeres debía respetarse el privilegio de no poder ser privadas de la libertad por deudas civiles. Bobadilla, en cambio, con base en la consideración de que "el genero masculino comprehende el femenino" y que "la intencion, y ánimo de la Ley se ha de considerar, y no las palabras", había estimado que también la esposa del comerciante, cuando desarrolla la actividad comercial y quiebra, debe ser sometida a las leyes del Reino establecidas para los deudores quebrados ${ }^{58}$.

En fin, según Hevia no se consideran pubblici fures aquellos deudores que se resguardan en las iglesias, o en otros lugares seguros, escondiéndose allí, y tampoco aquellos que incumplen sus obligaciones por falta de bienes, siempre que no los hayan ocultado. Respecto de estos sujetos, los soberanos habían dispuesto que se debía hacer justicia "conforme à la calidad de los negocios, como por la leyes de nuestros Reinos esta mandado" 59 .

\section{La tercera categoría de deudores quebrados}

"Estos son los que faltan por fraude, dolo, malicia, o culpa o vicio suyo, defraudando a sus acreedores en los bienes, o disipándolos, o consumiéndolos en juegos, amancebamientos, comidas, vestidos, y otros gastos excesivos y malos usos"60; los cuales fueron bien descritos por Stracca, quien los había considerado causa del indiscriminado juicio negativo de Baldo sobre los deudores insolventes ${ }^{61}$; es decir, quebrados que estaban preparados para todo tipo de maniobras -desde la venta al consumo de los bienes, hasta "intricarlos"- para evitar que los acreedores pudieran satisfacerse con ellos ${ }^{62}$.

57 Para un primer acercamiento a la temática (que tiene origen en la Xv Regula iuris de DiNO DEL MUGELLO, "Odia restringi et favores convenit ampliare", en el apéndice del Liber Sextus), con una mirada al derecho indiano, cfr. Bravo LiRA, B., “'Odia restringi'. Forma y destino de una regla del derecho en Europa e Iberoamérica, durante la Edad Moderna”, Ius Commune. Zeitschift für Europäische Rechtsgeschichte, XIX, 1992, 81-93 y BARRIENTOS GRANDÓN, J., "El 'mos italicus' en un jurista indiano. Francesco Carrasco del Saz (15?-1625)", Ius fugit. Revista interdisciplinar de estudios históricojurídicos, 2, 1993, 54-60. Hace referencia a esta regla y a sus orígenes también SBriccoli, M., L'interpretazione dello statuto. Contributo allo studio della funzione dei giuristi nell'età comunale, Milano, Giuffrè, 1969, 393, nt. 206.

58 Castillo de Bobadilla, J., Politica para corregidores y señores de vasallos, en tiempo de paz, y de guerra, II, Madrid, En la Imprenta Real de la Gazeta, 1775, L. 3, cap. 15, 329, nn. 34-37. En este sentido, explícitamente, en algún periodo previo, también Pedro NuñEZ de Avendaño, Tractatus seu declaratio ad l. Quartam et quintam tit. de las exceptiones lib. 3 Ordina. Regal., en ID., Quadraginta responsa, quibus quamplurimae leges regiae explicantur, atque illustrantur, Salmanticae, Apud haeredes Ioannis à Canova, 1576, fo. 166rb-va.

59 N. Recop., 5.19.5-6.

60 Hevia Bolaños, J. DE, Labyrintho de comercio, cit., p. 447, n. 10.

61 "Quoniam decoctorum singulariam fraudum genera novae insidiarum rationes, ad fraudandumque creditores excogitatae artes summa cum ratione stomachum Baldo nostro fecerunt, ut in eos inveheretur": STRACCA, B., De conturbatoribus, cit., pars 3, 479, n. 23.

62 Cabe destacar, como se evidenció en los escritos de Hevia, que en los mismos términos de Stracca se pronuncia el jurista indiano Juan de Matienzo, reportando al pie de la letra pasajes de De contur- 
Entre estos debían incluirse también aquellos comerciantes insolventes que no hubieran tenido los registros contables en regla o, peor aún, que los hubieran alterado: a esta conclusión llega Hevia refiriéndose una vez más a la $l$. Summa cum ratione y luego trayendo otros dos pasajes del Digesto -respectivamente, la Ait praetor $\S \mathrm{fi}$ ff. De servo corrupto (D. 11.3.1.5) y la l. Quidam ff. De in rem verso (D. 15.3.16)-, a los cuales se agregaba uno de las Instituciones ${ }^{63}$, comentado por Giasone $^{64}$.

Si esta última fuente no despertaba sorpresa, en cuanto reenviaba a la sedes materiae de la acción revocatoria ordinaria (la actio Pauliana) -donde eran inevitables las consideraciones relativas al fraude en perjuicio de los acreedores, presupuesto para el ejercicio de la acción misma- y así también la referencia al parágrafo final de la $l$. Ait praetor, donde se hablaba de un siervo que se hace "deteriore" para disminuir de forma ingeniosa el valor, más problemática parece la mención de la $l$. Quidam, que preveía el caso del amo que había arrendado a su siervo un fondo agrícola, con bueyes para trabajarlo, los cuales, sin embargo, no habían resultado idóneos para el uso, de modo que el hombre había solicitado al siervo venderlos y comprar otros; cosa que el siervo había hecho, pero sin pagar al vendedor de los nuevos bueyes, habiendo cobrado el precio de los bueyes y recibidos los nuevos.

En nuestro opinión, esta cita encuentra su razón de ser en el hecho de que el servus, del cual se hablaba en el texto, luego de haber cumplido el mandato del dominus, devino insolvente ("conturbaverat", dice el fragmento) ${ }^{65} \mathrm{y}$, en definitiva, no habiéndose comportado correctamente, había expuesto a su amo a responsabilidad frente al vendedor de los nuevos animales.

Igualmente, Hevia incluye dentro de los deudores quebrados de la tercera categoría también a aquellos que, aun siendo conscientes de sus deudas y de la insuficiencia de su patrimonio para la satisfacción de los acreedores; hubieran contraído otros deudas o estipulado negocios que perjudicaran a los mismos acreedores; también en este sentido, invoca un texto romano que, en su criterio, debería haber ofrecido un ejemplo concreto de este modo de operar.

Se trataba de la $l$. Si quis ff. Quae in fraudem credit. (D. 42.8 [9].15), en el cual el jurisconsulto Juliano se había ocupado de un deudor que, por testamento, había dado la libertad a sus siervos, haciendo desaparecer la garantía general de su acreedor Ticio, quien, sin embargo, mientras tanto, resultó satisfecho en su acreen-

batoribus; cfr. MATIENZO, J. DE, Commentaria in librum quintum recollectionis legum Hispaniae, cit., gl. 1 en tit. 19, 11.1 y 2, fo. 449vb-451ra, y gl. 1 en tit. 19, 1. 5, fo. 453rb-va.

63 Inst. 4.6 § Item si quis (Inst. 4.6.6).

64 Giasone, En § Item si quis, Inst. De actionibus (Inst. 4.6.6), en ID., De actionibus titulus Institutionum, cit., p. 114, n. 37, quien, al final, observa, con base en la autoridad de Bartolo, que "intricatio rationum facit praesumi fraudem creditorum". Carcassona precisaba que la enajenación de los mejores bienes era considerada comúnmente por los doctores como una presunción que fundaba el animus fraudandi (Additio l in § Item si quis, cit., p. 131).

65 Mientras que el caso de Viviano Tosco, en el sistema de glosas, añade la precisión -no presente en el texto romano, pero evidentemente fruto de interpretatio- de que el siervo "pecuniam redactam ex venditione boum perdidit". 
cia, convirtiéndose el testador en deudor de Sempronio. Ahora bien, se preguntó al jurista si el nuevo acreedor Sempronio habría podido demandar para solicitar la revocación de la libertad concedida, y Juliano respondió que no, con fundamento en que el fraude se hizo contra Ticio y no contra Sempronio. Este fragmento lo interpretó Bartolo, quien, más que detenerse en la solución ofrecida por el jurista romano, había observado que el hecho mismo de que el deudor supiera que tenía un acreedor y que sus bienes no eran suficientes para satisfacer las pretensiones de los acreedores configuraba el supuesto de fraude ${ }^{66}$; de modo que podía concluirse que "qui scit se habere creditores, et facultates suas non sufficere, videtur alienare in fraudem creditorum" 67 .

Tanto la insuficiencia de los bienes como la existencia de los acreedores son, según Hevia, de fácil prueba, "porque del hecho proprio no se puede pretender ignorancia" del deudor quebrado ${ }^{68}$, también aquí según un principio tomado del derecho común, cuya enunciación está acompañada de la indicación de un texto romano -la l. Quamquam ff. Ad Senatum Consultum Velleianum (D. 16.1.7 $)^{69}-$ y pocas, pero importantes, fuentes doctrinales: Bartolo ${ }^{70}$ y Giason del Maino ${ }^{71}$.

66 "Sed qualiter probatur debitorem fecisse in fraudem, Iurisconsultus dat practicam. Nam eo ipso quod scit se habere creditorem et scit sua bona non sufficere: tunc videtur fraudem facere"; cfr. BARTOLO DA SASSOFERRATO, en l. Si quis, cum haberet ff. Quae in fraudem credit. (D. 42.8 [9].15) en ID., Commentaria in primam Digesti novi partem, Lugduni, Excudebat Petrus Fradin, 1555, fo. 156rb.

67 Como, enfáticamente, se lee en el título del fragmento en cuestión, en la edición del siglo XVI del Corpus Iuris Civilis usado por nosotros (c. 564).

68 Hevia Bolaños, J. DE, Labyrintho de comercio, cit., 448, n. 13.

69 En el cual Papiniano había enseñado que un cierto garante perdía la posibilidad de replicar " quia non poterit facti ignorantiam praetendere".

70 Bartolo da Sassoferrato, en Auth. Sed cum testator C. Ad leg. Falcidiam (C.6.50 [49] en fi.), en ID., Commentaria in secundam Codicis partem, Lugduni, Excudebat Claudius Servanius, 1555, fo. $58 \mathrm{vb}$, n. 5-6. El maestro de la región de Las Marcas responde a la pregunta sobre si se debiera presumir que el testador conociese o no la dimensión de su patrimonio al momento de hacer el testamento, $\mathrm{y}$, frente a una decidida respuesta positiva de la Glosa, introduce una serie de distinciones. En primer lugar, se debe distinguir entre "actus morentium" y "actus viventium": en los primeros, "testator praesumitur ignorare vires sui patrimonii ... nisi ex aliqua qualitate praesumitur"; en los segundos, se debe distinguir posteriormente: si se trata de "bona ex novo", para los cuales "praesumitur ignorantia", o de "bona de antiquo", para los cuales se debe distinguir a su vez: si se trata de bienes inmuebles, para los cuales se presume el conocimiento, o de bienes muebles, para los cuales se debe considerar si se trata de "bona praesentia", para los que se presume el conocimiento, o de "bona absentia", para los que, en cambio, se presume la ignorancia. Después de esta minuciosa casuística, Bartolo observa que en aquellas ciudades donde existen los registros catastrales el propietario, debiendo inscribir sus bienes muebles e inmuebles para el pago de los impuestos, no podrá alegar que no tenía conocimiento de estos bienes, así que el sumo jurista termina enunciando el principio de mencionado texto: "Ego in his praesumerem scientiam, non enim esset tolerabilis ignorantia facti, in suo proprio, quod ita saepe rediret (n. 6)".

71 Giason de Maino, en § Item si quis, Inst. De actionibus (Inst. 4.6.6), cit., 115, que retoma a Bartolo en los pasajes citados en el texto, observando él también que "eo ipso quod quis scit habere creditores, item scit bona sua non sufficere creditoribus, alienando dicitur esse in fraude. Quod autem sciat se habere creditores, probatur de facili, si illos habuit ex facto suo" (según lo indicado por Hevia, Labyrintho de comercio, cit., n. ${ }^{\circ} 44$ y n. $\left.{ }^{\circ} 40\right)$. 
Otra clase de deudores quebrados que pertenece a esta categoría está representada por aquellos que, aprovechando la confianza de terceros, contraen deudas que saben de antemano que no podrán cumplir, dado que se muestran, con artificios fraudulentos, idóneos para hacer frente a sus obligaciones, cuando en la realidad no lo son. Y también en este sentido, el autor se apoya en textos romanos y de las Partidas que presentan ejemplos concretos de sujetos que integran el supuesto descrito.

En el primero -la $l$. Si quis ff. De dolo malo (D. 4.3.9) ${ }^{72}$ - se trataba, de hecho, de una suerte de devaluación intencionada del monto de una herencia, ejecutada por un sujeto con el fin de poderla adquirir a un precio más bajo del real ${ }^{73}$, mientras que en el segundo -la $l$. Saccularii ff. De extraordinariis criminibus (D. 47.11.7, pr.)se describían los denominados "saccularii", especie de estafadores profesionales, capaces de idear las más audaces maniobras engañosas ${ }^{74}$; y a estos últimos había dirigido la atención también una partida, hablando de "baratadores, e engañadores", quienes consiguen mostrar, con toda una serie de artificios, "que han algo, e non lo han"75.

Por último, según Hevia, deben incluirse en esta tercera categoría de deudores quebrados también aquellos que, expresa o presuntamente, en fraude a los acreedores liberan a un deudor suyo de las deudas que este tenga con ellos ${ }^{76}$, o pagan la propia deuda a uno de los acreedores en fraude y en perjuicio de los demás, concretando lo que, en términos actuales, podríamos definir una bancarrota preferencial ${ }^{77}$;

72 Nos parece necesario modificar un alegato de Hevia, que se refería a un $\S$ Si quis de una inexistente l. Falsus, en el título De dolo malo de las pandectas.

73 Sumamente esclarecedor el ejemplo práctico en el casus de referencia: "Institutus eras in quadam haereditate: et ego volebam eam emere: unde dixi eam vilem esse; et sic eam pro minori praetio dedisti".

74 Una glosa atribuida a Azzone nos los presenta, de manera gráfica, como aquellos "qui saccos ferunt plenos mercibus falsis, et falsis nummis, et cum eis solvitur pro merce pecunia, partem pecuniae furantur negantes se accipisse quantum acceperant, et quod reddunt, ex parte fuit dantis, ex parte eorum tantum. Et ideo fallunt retenta bona pecunia, cum sibi cambiri traditam poscunt". Es decir, "iaculatores" y personajes que "in saccis portant merces desuper bonas: inferius malas in eodem sacco", como precisa un glosador anónimo como conclusión de la misma glosa.

75 Partidas, 7.16.9. Del engaño que fazen los baratadores, mostrando que han algo, e non lo han. Obsérvese que Gregorio López (gl. Sacos o bolsas, a dicha ley) reenvía explícitamente a la l. Saccularii.

76 De estos deudores se había interesado una ley (Partidas, 5.15.12. Como deven ser revocados los quitamientos, que fazen los omes a sus debdores, maliciosamente), que reconocía la posibilidad para los acreedores de ejercitar la acción revocatoria, siempre que "fueren sabidores del engaño, aquellos aquien quitan el debdo", como estaba previsto -nos permitimos recordar- desde el derecho romano, como presupuesto para su ejercicio (el llamado consilium fraudis). Y López, resumiendo el contenido de la ley, no puede sino confirmar -diríamos: como buen romanista- la premisa: "Liberatio seu quitatio in fraudem creditoris facta revocatur: si liberatus particeps fraudis fuit".

77 Para usar una definición adoptada por el legislador italiano en el artículo 216 c. 3 de la Ley de Quiebra (R.D. 16 de marzo de 1942, n. 267). 
y así también, deben incluirse todos aquellos que, con cualquier contrato o acto en perjuicio de sus acreedores, incurran en el llamado crimen stellionatus $^{78}$.

Contra todos estos deudores quebrados se debía proceder penalmente: en caso de condena ellos se enfrentaban a penas arbitrarias previstas por el derecho real de acuerdo con la gravedad del hecho -que podían llegar hasta la pena de muerte- y a una serie de sanciones accesorias, como la pena de infamia, la inhabilitación para el ejercicio de la actividad mercantil y la confiscación de los bienes en beneficio de la Cámara Real ${ }^{79}$.

Un problema particularmente relevante en la época era aquel de si los deudores quebrados gozaban o no del privilegio de la inmunidad, en el caso de que se hubieran refugiado en una iglesia o en otro lugar sacro; la pregunta había dado lugar a muchas discusiones en el ámbito de la scientia iuris de la edad moderna y no solo porque envolvía problemáticas muy delicadas, contrastantes entre sí: de una parte, la libertas ecclesiae, que debía ser salvaguardada y, de otra parte, la facultas puniendi del poder civil, que no se podía poner en crisis, sobre todo en un momento en el cual se estaban consolidando los Estados nacionales ${ }^{80}$.

Ayudado en esto también por la existencia de una abundante legislación real ${ }^{81}$, Hevia afirma que los deudores insolventes de esta tercera categoría son asimilables a los pubblici fures et latrones y por esto no gozan de la inmunidad local, a diferencia de las otras clases de deudores quebrados que sí pueden utilizarla para su propio provecho $^{82}$, salvo en el caso de los bienes y los libros contables eventualmente es-

78 Sobre los cuales D. 47.20. Un supuesto bastante indeterminado de delito que, al menos según la romanística dominante, servía para reprimir actos dolosos que, aunque causaran daños a otros, no eran atribuibles a figuras delictuales específicas. Casi poética, pero eficaz, la explicación etimológica del significado en la gl. Stellionatus, en $l .2$ ff. De crimine stellionatus (D.47.20.2): "Dicitur sic a quodam animali quod stellio vocatur: et est varii et diversi coloris: ut coelum stellis apparet oculis tinctum: cuius varietatem imitantur deceptores: quia varia agunt, et alius simulant, et aliud dicunt". Ejemplos de estas maniobras se pueden encontrar en STRACCA, De conturbatoribus, cit., pars 3, 479480, nn. 28-32, tomado expresamente de MATIEnzo, Commentaria in librum quintum recollectionis legum Hispaniae, cit., gl. 1 en tit. 19, 11. 1 y 2, fo. 450vb-451ra, nn. 11-13.

79 "Reges catholici nostri poenas varias statuerunt, nempae, ut pro publicis seu famosis latronibus habeantur", observa MATIENZO, Commentaria in librum quintum recollectionis legum Hispaniae, cit., gl. 2 en tit. 19, 11.1 y 2, fo. $451 \mathrm{vb}$, antes de realizar un análisis prudente de las mismas, en el comentario de la totalidad del título 19.

80 La problemática fue estudiada funditus por Speciale, G., Fallimento tra Dolo e Sfortuna. L'azione revocatoria e il diritto d'asilo nei secoli XVI-XVIII, Roma, Il Cigno Galileo Galilei, 1996, pp. 121-137 y por Latini, C., Il privilegio dell'immunità. Diritto d'asilo e giurisdizione nell'ordine giuridico dell'età moderna, Milano, Giuffrè, 2002, 280-304.

81 Véanse en N. Recop. 1.2 De la libertad, i exempcion de las Iglesias, i Monasterios, i guarda de sus bienes, en partic. las leyes 1, 2, 6 y 13; sin embargo, también N. Recop., 5.19.2, según la cual los alzados eran llamados "publicos ladrones, i verdaderos robadores".

82 La cuestión, controvertida en general en la scientia iuris europea, lo era también en España, donde todo giraba en torno a la interpretación de $N$. Recop., 1.2.13, que, excluyendo la inmunidad eclesiástica para "los que tienen obligadas sus personas por qualesquier deudas, que devan, aunque despues de hechas las tales obligaciones", según la mayor parte de la doctrina (un análisis detallado en Covarrubias y Leyva, D., Variae ex iure Pontificio, Regio et Caesareo resolutiones, en ID., Operum 
condidos en los lugares de asilo, que podrán ser tomados en cualquier momento por la autoridad competente por cuenta de los acreedores ${ }^{83}$.

Igualmente los deudores insolventes de esta tercera categoría pueden recuperarse "de qualesquiera fortalezas, castillos, casas de morada o lugares en que estubieren" $"$, cuando haya costumbres o privilegios que impidan esta captura y así también de uno de los Reinos que hacen parte de la Corona de España, para ser entregados al juez que tenga la jurisdicción ${ }^{85}$.

En fin, concluye Hevia, no podrán en ningún modo utilizar el instrumento procesal de la bonorum cessio ${ }^{86}$.

\section{La quiebra entre codificación y derecho novohispano: del antiguo derecho indiano al código de comercio mexicano de 1854}

El trabajo interpretativo de la ciencia jurídica sobre la quiebra, que hemos intentado describir a grandes rasgos, estaba destinado a continuar por todo el Ancien Régime y más allá, sin detenerse ni siquiera frente al gran fenómeno de la codificación del derecho comercial, dado que el código de comercio napoleónico, como bien se sabe,

tomus secundus, Coloniae Allobrogum, Sumpt. Cramer, Perachon et Cramer filii, 1723, L. 2, cap. 20, 260-261, n. 14), debía referirse solo al comerciante quebrado, "vulgo alçado", ya considerable "publicus latro", en el sentido del c. Inter alia x. De immun. Eccl. (x. 3.49.6), mientras que el simple "debitor civilis" la habría disfrutado y con él también el "mercator solutus, vulgo quebrado", porque no se consideraban tales; cfr. ACEVEDo, A. DE, Commentariorum Iuris civilis in Hispaniae Regis constitutiones ... tomus primus, Madriti, En aedibus Petri Madrigal, 1599, En L. 1, tit. 2, 1. 13, 47, n. 6 (del que se extraen las expresiones entre comillas); Hevia, Curia Philipica, I, cit., parte 3, § 12, 216-217, n. 42, y el Covarrubias, loc. ult. cit. No obstante, no faltaban autores -también de pesoque tendían a extender esta exclusión del privilegio; cfr. BoBadilla, Politica para corregidores, I, cit., L. 2, cap. 14, 492-493, n. 65: "La verdad es en contrario, y que non debe gozar el tal deudor [aquel simple, se entiende] de la inmunidad Eclesiastica y asi se usó por leyes de los Visigodos". El fundamento de esta opinión residiría precisamente en la ley 13 en cuestión, que fue promulgada por los Reyes Católicos a petición de la ciudad de Sevilla; disposición que, concluye Bobadilla, "aunque parece dura, está asi escrita".

83 Cfr., además de la ley 13, a la que se refiere la nota anterior, también N. Recop., 5.19.2, al tenor de la cual, si algunos bienes de los deudores quebrados fraudulentos se encontraban "en algunas Iglesias, ò Monasterios, ò Hospitales, ò Fortalezas, ò en otras qualesquier partes, i Lugares”, debían ser tomados "para que de alli se paguen los acreedores de lo que les fuere devido".

84 Hevia Bolaños, J. DE, Labyrintho de comercio, cit., p. 451, n. 19.

85 Existían, en este sentido, algunas disposiciones, definidas por el derecho internacional, que lo preveían expresamente: $N$. Recop., 8.16.2-6-7.

86 Y esta era una consecuencia -se diría: obvia- de la insolvencia, dado que "decoctus pro mortuo habetur, et nihil potest agere, et perdit administrationem bonorum", para usar los términos de DíEZ Noguerol, P., Allegationes iuris, Lugduni, Sumptibus Petri Borde, Joannis, et Petri Arnaud, 1693, all. 16, 144, n. 101. De todos modos, en caso de que el deudor quebrado la hubiera hecho, habría sido nula e ineficaz precisamente por el hecho de que había perdido la administración de sus bienes (así Costa, G. B., Novus, de quota, et rata, sive de congrua in iure rerum partitione, tractatus, Francofurti, E Collegio Musarum Novenarum Paltheniano, 1606, quaes. 70, 144, n. 6). 
pretendió renovar una postura de extrema dureza frente a los deudores quebrados dolosamente, también por voluntad del mismo Napoleón ${ }^{87}$.

Basta ver lo que escribía Jean-Baptiste-François Delaporte en sus Pandectes françaises, comentando el libro tercero del Code de commerce pocos años después de su promulgación, cuando observaba la severidad de las disposiciones allí contenidas; una severidad que, en su opinión, se hizo necesaria debido a la "depravación de las costumbres llevada hasta el último extremo por los desórdenes de la revolución" y a los "excesos de lujo desenfrenado que socaba y absorbe las fortunas más opulentas", ya que el comercio se había convertido en un verdadero "latrocinio" y las quiebras en un medio para hacer fortuna. Por lo tanto, ante esta situación, "era urgente frenar la licencia, otorgar una protección eficaz a la industria laboriosa y honesta, contra la codicia emprendedora y astuta", culpando la mala fe y la imprudencia, pero protegiendo a aquellos comerciantes desafortunados que habían sido afectados por la mala suerte en sus negocios honestos ${ }^{88}$.

Como se sabe, el fenómeno codificador extendió su influencia también a los países de América Latina, con diferentes resultados y desarrollos de un país a otro, que no es posible considerar aquír ${ }^{89}$. Sin embargo, nos pareció pertinente hacer al menos una mención a la experiencia mexicana porque justamente a mediados del siglo XIX encontramos una edición de la Curia Filípica (dentro de la cual está también el Labyrintho) que, sin embargo, no constituye una simple reimpresión de la Curia de Hevia Bolaños, sino que es el resultado de un proceso, definido de mexicanización; proceso que involucró a muchas otras obras doctrinales españolas ${ }^{90}$.

Esta apareció en un momento particularmente complejo de la historia mexicana, con la transición del periodo colonial al de la independencia y la sucesión de varias formas de gobierno; un periodo en el cual, para lo que aquí interesa, el derecho co-

87 Lo recuerda PAdoA Schioppa, A., "Codificazione e legislazione commercialistica in Francia (17781915)", e ID., "Napoleone e il 'Code de commerce"”, ambos ahora en ID., Saggi di storia del diritto commerciale, Milano, LED, 1992, respectivamente 73 y 92-94; más recientemente TETI, R., Un diritto per gli imprenditori. Il diritto commerciale dalle codificazioni ottocentesche al codice civile del 1942, Roma, Donzelli, 2018, 12-18.

88 Delaporte, J.-B.-F., Les Pandectes françaises ou recueil complet de toutes les lois en vigueur, $\mathrm{xx}$, Code de commerce, Paris, Garnery, 1812, 248.

89 Para el fenómeno en general, cfr. GUZMÁn BRITO, A., Historia de la codificación civil en Iberoamérica, Fundación Histórica Tavera, 2000 y los ensayos recogidos en CruZ BARNEY, O. (coord.), $L a$ codificación, México, Porrúa, 2006.

90 Escribió González, M. Del R., Historia del derecho mexicano, México, unam, 1997, 48, que en este periodo hubo muchas obras que retomaron las obras españolas y las "mexicanizaron, ya que se agregaba en cada edición, la legislación mexicana vigente”. En la primera edición de su manual, la autora había precisado además que los autores eran en su mayoría anónimos, pero todos motivados por la intención de ofrecer instrumentos para adentrarse en el intrincado campo de la legislación vigente (GonzÁlez, M. Del R., Historia del derecho mexicano, México, unam, 1983, 48). Otro ejemplo, además de la Curia, está representado por la Ilustración del Derecho real de España (primera edición: 1803) del catedrático de Valencia Juan Sala; cfr. Peset, M., "Novísimo Sala mexicano o el final del viejo derecho hispano", en BERnal, B. (coord.), Memoria del IV Congreso de Historia del Derecho Mexicano (1986), II, México, unAm, 1988, 895-913. 
mercial, en busca de modelos jurídicos propios y no satisfecho con los de importación $^{91}$, debía hacer frente al caos normativo, derivado de la estratificación, ocurrida durante siglos, de normas dispersas. Es por eso por lo que, con ayuda de la práctica judicial, aparecieron obras como la que se acaba de citar, que servían a los jueces mismos "para desempeñar su función" 92.

El autor de esta verdadera reelaboración de la Curia es probablemente un jurista práctico, Juan Nepomuceno Rodríguez de San Miguel (1808-1877), quien era ya famoso por haber escrito, un par de décadas antes, otra obra dirigida "a elaborar herramientas para el beneficio de todos" 93 y, en últimas, a aclarar el derecho vigente: las muy afortunadas Pandectas hispano-megicanas ${ }^{94}$.

Era entonces un testigo confiable de la efectiva percepción del hecho quiebra en el ámbito de la sociedad y de la praxis judicial de aquel periodo.

Luego de haber recordado que "un negociante ó banquero hace bancarrota, cuando falta al pago de sus débitos, bajo el pretesto verdadero ó fingido de no hallarse en estado de poder satisfacerlo" "95, y que la distinción entre "bancarrota" (insolvencia dolosa) y "quiebra" (insolvencia debido a un infortunio) con frecuencia no se sigue puntualmente por el legislador, de manera que los dos términos se usan de forma indistinta para indicar la "falta de pago" $"$, Rodríguez pasa a un tratamiento de

91 GonZÁlez, M. DEL R., "Comercio y comerciantes en la legislación y la doctrina mexicanas del siglo XIX”, Anuario Mexicano de Historia del Derecho, II, 1990, 115-149.

92 GonzÁlez, M. DEL R., Historia del derecho, 1997, cit., 47. Recientemente se ha observado que la Curia se consideraba "como libro de consulta obligada en la práctica y como manual de enseñanza". LiRA, A., "Derecho e historia", en Historia del derecho ¿para qué?, Valencia, Tirant lo Blanch, 2020, 61. Para el uso de la Curia en las universidades españolas, cfr. MARTínEz NeIRA, M., "Lecturas antiguas y lecturas ilustradas. Una aproximación a los primeros manuales jurídicos", Cuadernos del Instituto Antonio de Nebrija, I, 1998, 151-153, 158.

93 González Domínguez, M. Del R., "Juan N. Rodríguez de San Miguel jurista conservador mexicano", en González Martín, N. (coord.), Estudios jurídicos en homenaje a Marta Morineau, I, Derecho romano. Historia del derecho, México, unAM, 2006, 241, quien considera a este autor "uno de los más grandes juristas mexicanos". En ID., Comercio y comerciantes, cit., extrañamente con una sola mención a la Curia, por lo demás atribuida al librero-editor Mariano Galván Rivera (p. 135, nota 68). La reimpresión de la obra (1978), en la Nueva Biblioteca Mexicana, coordinado por la unAm, atribuida a Rodríguez.

94 Rodríguez de SAn Miguel, J. N., Pandectas hispano-megicanas ò sea Código general comprensivo de las leyes generales, útiles y vivas..., Mégico, Impreso en la oficina de Mariano Galván Rivera, 1839; obra considerada, con razón, "uno de los textos más famosos del siglo XIX” (así GonzÁLEZ, M. DEl R., "Introducción”, a Rodríguez de SAn Miguel, J. N., Pandectas hispano-mexicanas, I, México, UNAM, 1980 [reprod. de la ed. Méjico, 1852], IX), de la cual se recibe, entre otras, el carácter legicéntrico de la recepción del ius commune en la Nueva España, como ha puesto de manifiesto oportunamente Estrada Michel, R., "Las relaciones entre México y el 'ius commune’ europeo. ¿Difusión, recepción, resistencia o mestizaje?”, en LANDI, A. (coord.), Esperienze giuridiche latino-americane e diritto comune romano-canonico. Saggi, Torino, Giappichelli, 2018, 84.

95 [Rodríguez de San Miguel, J. N.], Curia Filípica Mexicana. Obra completa de practica forense, México, Mariano Galván Rivera, 1850, parte 5, § 15, 801, n. 439. 
la figura del quebrado que, sin dejar de estar vinculada a la trama del Labyrintho ${ }^{97}$, ofrece una serie de actualizaciones principalmente derivadas de la legislación sucesiva y, en particular, de las Ordenanzas de Bilbao del 1737 ${ }^{[98]}$.

Advierte Rodríguez que en tal recopilación se distinguen tres categorías de deudores quebrados: los primeros son aquellos que no pagan sus deudas en el plazo acordado, porque carecen de la liquidez necesaria; los segundos son aquellos que se encuentran en el estado de insolvencia sin culpa, sino más bien por causa de "accidentes imprevistos"; el tercer grupo es el de los "quebrados fraudolentos".

Respecto de la primera tipología de deudores quebrados, al momento de adoptar cualquier iniciativa en su contra se debe tener en cuenta "el honor de su crédito, buena opinion y fama" ${ }^{99}$; mientras que no se puede proceder de ninguna manera en contra de los segundos, quienes, sin embargo, sufrirán una especie de suspensión de sus derechos de ciudadanos, hasta que no hayan cumplido sus obligaciones.

Sobre los deudores quebrados dolosamente propone de manera sintética todas las figuras ilustradas por Hevia, recordando que contra ellos se procede también penalmente por el delito cometido ${ }^{100}$ y que tales sujetos incurren en la pena de infamia y en aquellas arbitrarias "segun el grado de la culpa ó malicia, y la mayor ó menor importancia de los negocios". Además, están permanentemente prohibidos del ejercicio del comercio y, con base en la ley mexicana del 12 de julio de 1930, privados incluso "de los derechos de ciudadano"101.

Más allá de la clasificación innovadora, quedaba claro que la disciplina de la quiebra se caracterizaba por la protección de los intereses de los acreedores, dado

97 Como recuerda el mismo Rodríguez, en la Introduccion, su idea inicial era aquella de continuar con una nueva edición de la Curia Filípica, con la inclusión de la novedad legislativa y la supresión de todo el derecho antiguo que ya no estaba vigente, pero luego le pareció más conveniente "hacer una completa refundicion [...] y presentar bajo un órden sistemático, las disposiciones legislativas y las prácticas que se han sucedido en el transcurso de los siglos y forman nuestra jurisprudencia moderna”.

98 Las cuales, una vez "trasladadas a Hispanoamérica, estuvieron en vigencia en muchos países [...] hasta la adopción del Código de Comercio, lo cual significó que aún derogadas en España regían en las antiguas provincias de ultramar". Así Morales Hernández, A., Curso de derecho mercantil, I, Introducción. La empresa. El empresario, Caracas, Universidad Católica Andrés Bello, 2007, 22. Para México, habiendo permanecido las Ordenanzas impermeables al proceso de independencia y también al Código de Lares (1854), que tenía una función subsidiaria respecto de aquella, véase Portalés Trueba, C., Derecho mercantil mexicano, I, Nociones básicas y generales, Ciudad Juárez, Universidad Autónoma de Ciudad Juárez, 2012, 35-37. Para una valoración de esta recopilación como "obra normativa de raíz más práctica que teórica, más consuetudinaria que doctrinal”, cfr. Tomás y Valiente, T. Manual de historia del derecho español, cit., 367 y, más ampliamente, Petit, Historia del derecho, cit., 145-161.

99 Curia Filípica Mexicana, cit., 802, n. 442.

100 En este sentido, se puede decir que las consideraciones de Rodríguez se inscriben en el recorrido de la ciencia jurídica y de las prácticas del tardío derecho común sobre la calificación de la quiebra dolosa como hurto o estafa, o como delito autónomo de bancarrota. Sobre estas reflexiones cfr. SciumÈ, A., Ricerche sul fallimento nel diritto moderno, I, Il momento settecentesco, Milano, Giuffrè, 1985, 81 , con referencia específica a la legislación francesa y a algunos Estados italianos.

101 Curia Filípica Mexicana, cit., 803, n. 449. 
que en las mismas Ordenanzas se había resaltado que la reducción a tres clases de deudores quebrados se hizo para evitar "disensiones, y pleytos largos, y costosos", beneficiando así al mercado en general (“causa publica de este Comercio”) ${ }^{102}$.

Por lo demás, también en otra obra española, sometida por Rodríguez a aquel proceso de mexicanización mencionado -el Diccionario razonado de Joaquín Escriche ${ }^{103}$ - se observan, además de una evidente cercanía con la terminología francesa, referencias tanto a las Ordenanzas de Bilbao, como a la Curia Filípica, con el resultado de que surge una clasificación aún más reducida, debido a que las tipologías de deudores quebrados que quedan son solamente dos: aquella de los "quebrados inculpables" y la de quienes, aun conociendo sus malas condiciones, "arriesgan no obstante con dolo y fraude los caudales agenos" 104 .

En resumen, Rodríguez parece explicar, también aquí, las contradicciones de su época fluctuando entre novedad y conservación ${ }^{105}$.

Al momento de la codificación mexicana de 1854 el interrogante principal estaba aún abierto: el Código de Lares, de hecho, si bien constituyó en muchos aspectos una adaptación del Código Comercial español de $1829^{[106]}$, no establecía una lista de los tipos de deudores quebrados, como había hecho el anterior ${ }^{107}$, sino que repetía,

102 Ordenanzas de la Universidad, y casa de contratacion de la m.n.y m.l. Villa de Bilbao, Madrid, En la oficina de D. Antonio Fernandez, 1775, cap. 17, n. 1, 126.

103 EsCRICHE, J., Diccionario razonado de legislación civil, penal, comercial y forense ... con citas del derecho, notas y adiciones por el licenciado J. Rodríguez de San Miguel, Mégico, Impreso en la oficina de Galván, 1837. Sobre esta obra, que aparece por primera vez en París en 1831, y sobre las operaciones realizadas por el jurista mexicano, cfr. GonZÁLEZ, M. DEL R., "El derecho indiano en el Diccionario de Escriche anotado por Rodríguez de San Miguel”, en Memoria del x Congreso del Instituto Internacional de Historia del Derecho Indiano, I, México, ELD-unAm, 1995, 543-570; sobre Escriche (1784-1847), cfr. Marina MarTín, J., "Don Joaquin Escriche y Martín y sus obras", Anuario de Derecho Aragonés, vi (1951-52), 63-75.

104 EsCRICHE, Diccionario razonado, cit., 65, s.v. "Bancarrota". Mientras que en los escritos originales estaba también el autor quebrado, donde se hablaba de la "insolvencia fortuita", de la "culpable" y luego de aquella "fraudolenta" (aún presente en Escriche, J., Diccionario razonado de legislación civil, penal, comercial y forense ... publicado en Valencia de España en 1838, Caracas, Imprenta de Valentin Espinal, 1840, s.v. "Quebrado", 550-551), en la versión de Rodríguez se omite dicha voz, ya que se nota la excesiva correspondencia con el código de comercio español (p. 589, nota 1), con el resultado ya anotado.

105 Nos parece expresión de esta vaga postura la aversión del conservador Rodríguez con respecto al derecho romano al cual quiere preferir en la enseñanza universitaria del derecho nacional, aunque, de iure condendo, su idea de código sea bastante alejada de lo que se estableció con la codificación napoleónica, teniendo, entre otras, un fuerte carácter confesional; cfr. MorinEAU, M., "Dos juristas mexicanos del siglo xix: Antonio Florentino Mercado versus Juan Rodríguez de San Miguel", Anuario Mexicano de Historia del Derecho, 1997, IX, 1997, 179-191; "Dictamen de la Comisión de Reglamento, sobre formación de Códigos”, en Rodríguez de SAN Miguel, J. N., Escritos jurídicos (1839-1863). Antología, GonzÁlez, M. DEL R. (coord.), México, unam, 1992, 189-198, y aquí GonZÁLEZ, M. DEL R., "Estudio preliminar", 27-28.

106 González, M. DEL R., Comercio y comerciantes en la legislación y la doctrina, cit., 135.

107 El Código de Sainz de Andino, luego de haber definido el "estado de quiebra" como aquel en que se encuentra el comerciante que suspende el pago ordinario de sus obligaciones (art. 1001), enlistaba cinco clases de quiebras en el art. 1002: 1. Suspensión de los pagos, 2. Insolvencia fortuita, 3. In- 
en los primeros artículos del libro dedicado a las Quiebras ${ }^{108}$, los presupuestos, objetivo y subjetivo, de la quiebra, identificados respectivamente en la suspensión del pago por parte del deudor de sus obligaciones "líquidas y cumplidas" (art. 759) y en el hecho de que él tuviera la "calidad de comerciante" (art. 761) ${ }^{109}$.

Luego, se presuponía la existencia de varios tipos de quiebras, pero solo se tomaban en consideración la "quiebra culpable" y la "fraudolenta" (art. 763), para, en primer lugar, cambiar de jurisdicción, que pasaba de la ordinaria civil y penal a la especial, fijada por el mismo Código ${ }^{110}$.

Después de la entrada en vigor de este código, José Julián Tornel y Mendívil no podrá hacer otra cosa que registrar, en su Manual, esta situación ${ }^{111}$.

\section{Conclusiones}

No es posible dejar de observar que la cualificación del hecho quiebra ha evolucionado desde la indiscriminada condena medieval a una distinción de hipótesis que tengan en cuenta las distintas causas que la provocan, aunque nunca se llegue a una consideración del mismo como una cuestión exclusivamente económica (la pura crisis de la empresa, como se diría hoy) ${ }^{112}$ : de una parte, está la quiebra dolosa, fruto de las maniobras deshonestas del comerciante; de otra parte, una insolvencia causada por fuerza mayor; y en medio, toda una serie de hipótesis en las que la impericia y la negligencia del comerciante, además de hechos no imputables a él, determinaron la insolvencia. La scientia iuris del derecho común clasifica estas hipótesis, con una precisión y una atención que puede parecer que responde a un desarrollo casuístico pero que, en su lugar, es fruto de la evolución que la institución sufre desde sus orígenes en el contexto de la sociedad mercantil del bajo medioevo -que las consideraba tout court como antijurídicas, por cuanto socavaban los fundamentos de

solvencia culpable, 4. Insolvencia fraudulenta y 5. Alzamiento, definiéndolo luego en los artículos sucesivos (respectivamente arts. 1003, 1004, 1005-1006, 1007 y 1008).

108 Libro IV, tit. 1, Disposiciones generales.

109 Obsérvese que, precisamente aquí, el Código recuerda que son comerciantes "los que teniendo capacidad legal para ejercer el comercio, hacen de él su ocupacion habitual y ordinaria" (art. 760), con lo cual indudablemente invoca la noción definida por el Code de commerce napoleónico en su primer artículo.

110 A la apreciación de la tipología se dedicó todo el título x del libro Iv (arts. 887-910 - De la calificacion de la quiebra).

111 Tornel y Mendivil, J. J., Manual de derecho mercantil mexicano ó sea el Código de comercio de México puesto en forma de diccionario, México, Imprenta de Vincente Segura, 1854, s.v. "Calificacion de quiebra", 16-20 y s.v. "Quiebra", 146-148. Un panorama sobre la codificación del derecho comercial y sobre las distintas reformas, a partir de la abolición del consulado en 1824, hasta llegar al código de 1889 aún vigente, entre tantos, en CRUZ BARNEY, O., La codificación en México: 18211917. Una aproximación, México, unAM, 2004, 78-94, y también en BARRERA GrAF, J., "Evolución del derecho mercantil en México en el siglo xIx hasta el Código de Comercio vigente de 1890", en Memoria del IV Congreso de Historia del Derecho Méxicano (1986), cit., 111-143.

112 Cfr. Santarelli, U., Mercanti e società tra mercanti ${ }^{3}$, Torino, Giappichelli, 1998, pp. 65-84. 
aquella sociedad (fiducia, crédito y comercio) - y luego de su posterior ocaso, que había dejado su lugar a los Estados nacionales y al incipiente capitalismo de la edad moderna.

También la experiencia del derecho indiano no se sustrae, entonces, a la originaria percepción típica del ius mercatorum. Si bien Hevia distinguía, como hemos visto, las distintas tipologías de deudores quebrados, deja ver, en todo caso, el aura de descrédito que rodea al instituto de la quiebra y al comerciante que incurre en ella. Y así ocurrirá también con las codificaciones comercialistas de del siglo XIX que retoman las elaboraciones doctrinales consolidadas.

Deberán transcurrir un par de siglos, con profundos cambios políticos y sociales, para que el legislador y los juristas comiencen a mirar a la quiebra con otros ojos y a hablar finalmente de una second chance policy para el deudor quebrado ${ }^{113}$.

Solo la ciencia del derecho comercial podrá decirnos, dentro de algún tiempo, cuáles serán los efectos de esta actual política del derecho.

\section{Referencias}

\section{Fuentes históricas}

Acevedo, A. DE, Commentariorum iuris civilis in Hispaniae Regias constitutiones, Quintum librum Novae Recopilationis complectens, tomus tertius, Salmanticae, Excudebat Petrus Lassus, 1597.

Acevedo, A. De, Commentariorum Iuris civilis in Hispaniae Regis constitutiones, Tres priores libros Novae Recopilationis complectens, tomus primus, Madriti, In aedibus Petri Madrigal, 1599.

Antonio, N., Bibliotheca Hispana nova sive Hispanorum scriptorum qui ab anno 1500 ad 1684 floruere notitia, I, Matriti, Apud Joachimum de Ibarra typographum regium, 1783 (reimp. anastática, Torino, Bottega d'Erasmo, 1963).

Bartolo da Sassoferrato, Commentaria, III, In primam Infortiati partem, Venetiis [L.A. Giunti], 1602.

Bartolo da Sassoferrato, Commentaria in primam Digesti novi partem, Lugduni, Excudebat Petrus Fradin, 1555.

113 Para Italia, el reenvío es a la ley del 19 de octubre de 2017, n. ${ }^{\circ} 155$, y al siguiente Decreto legislativo del 12 de enero de 2019 n. ${ }^{\circ}$ 14, promulgado en aplicación de la misma. Sobre estas problemáticas, entre una amplísima bibliografía, véase la ágil elaboración de Nuzzo, G., "Le conseguenze personali del fallimento dalla "morte civile" alla politica della seconda opportunità", en Landi, A. y Petrucci, A. (coord.), Pluralismo delle fonti e metamorfosi del diritto soggettivo nella storia della cultura giuridica, I, La prospettiva storica, Torino, Giappichelli, 2016, pp. 215-235. 
Bartolo da Sassoferrato, Commentaria in secundam Codicis partem, Lugduni, Excudebat Claudius Servanius, 1555.

Castillo de Bobadilla, J., Politica para corregidores y señores de vasallos, en tiempo de paz, y de guerra, II, Madrid, En la Imprenta Real de la Gazeta, 1775.

Costa, G. B., Novus, de quota, et rata, sive de congrua in iure rerum partitione, tractatus, Francofurti, E Collegio Musarum Novenarum Paltheniano, 1606.

Covarrubias y Leyva, D., Variae ex iure Pontificio, Regio et Caesareo resolutiones, en ID., Operum tomus secundus, Coloniae Allobrogum, Sumpt. Cramer, Perachon et Cramer filii, 1723, 1-487.

Delaporte, J.-B.-F., Les Pandectes françaises ou recueil complet de toutes les lois en vigueur, $\mathrm{xx}$, Code de commerce, Paris, Garnery, 1812.

Díez Noguerol, P., Allegationes iuris, Lugduni, Sumptibus Petri Borde, Joannis, et Petri Arnaud, 1693.

ESCRICHE, J., Diccionario razonado de legislación civil, penal, comercial y forense ... con citas del derecho, notas y adiciones por el licenciado J. Rodríguez de San Miguel, Mégico, Impreso en la oficina de Galván, 1837.

EsCRICHE, J., Diccionario razonado de legislación civil, penal, comercial y forense ... publicado en Valencia de España en 1838, Caracas, Imprenta de Valentin Espinal, 1840.

Giasone del Maino, De actionibus titulus Institutionum, Francofurti ad Moenum, 1581.

Giovanni Battista Caccialupi, De debitore suspecto et fugitivo, en Tractatus universi iuris, $\mathrm{III} / 2$, Venetiis 1584 , fo. 148ra-155rb.

GiovanNi Della PiazZa, Super quatuor Institutionum lib., s.d.e., 1539.

Hevia Bolaños, J. De, Curia Philipica, I, Madrid, Por Ramon Ruiz, en la Imprenta de Ulloa, 1790.

Hevia Bolaños, J. DE, Labyrinthus commercii terrestris et navalis e patrio hispano idiomate in latinum versus, Florentiae, Typis Regis Celsitudinis, apud Petrum Antonium Brigonci, 1702. 
Hevia Bolaños, J. DE, Labyrintho de comercio terrestre y naval, En Lima, Por Francisco del Canto, natural de Medina del Campo, 1617.

Jean Faure (FABer), In Institutiones Commentarii, Lugduni, Excudebat Petrus Fradin, 1557.

Las siete Partidas glosadas por el Licenciado Gregorio López, En Salamanca, Por Andrea de Portonariis, 1555 (ed. facsimilar, Madrid, Boletín Oficial del Estado, 1974).

Matienzo, J. DE, Commentaria in librum quintum recollectionis legum Hispaniae, Mantuae Carpentanae, Excudebat Petrus Madrigal, 1597.

Nuñez de Avendaño, P., Tractatus seu declaratio ad l. Quartam et quintam tit. de las exceptiones lib. 3 Ordina. Regal., en ID., Quadraginta responsa, quibus quamplurimae leges regiae explicantur, atque illustrantur, Salmanticae, Apud haeredes Ioannis à Canova, 1576, fo. 133ra-166vb.

[Rodríguez de San Miguel, J. N.], Curia Filípica Mexicana. Obra completa de practica forense, México, Mariano Galván Rivera, 1850.

Rodríguez de SAn Miguel, J. N., Escritos jurídicos (1839-1863). Antología, M. DEL R. GonZÁlez (coord.), México, unam, 1992.

Rodríguez de San Miguel, J. N., Pandectas hispano-megicanas ò sea Código general comprensivo de las leyes generales, útiles y vivas..., Mégico, Impreso en la oficina de Mariano Galván Rivera, 1839.

Solórzano y Pereira, J. De, Politica indiana, Amberes, Por Henrico y Cornelio Verdussen, 1703.

STRACCA, B., Tractatus de conturbatoribus sive decoctoribus, en De mercatura decisiones et tractatus varii, Lugduni, P. Landry, 1610 (reimp. anastática, Torino, Bottega d'Erasmo, 1971).

STRACCA, B., De mercatura seu de mercatore tractatus, in Tractatus Universi Iuris, vi/1, Venetiis, 1584, fo. 284rb-303ra.

Tornel y Mendivil, J. J., Manual de derecho mercantil mexicano ó sea el Código de comercio de México puesto en forma de diccionario, México, Imprenta de Vincente Segura, 1854. 


\section{Fuentes modernas}

Barrera Graf, J., "Evolución del derecho mercantil en México en el siglo Xix hasta el Código de Comercio vigente de 1890", en Bernal, B. (coord.), Memoria del IV Congreso de Historia del Derecho Mexicano (1986), II, México, unAm, 1988, 111-143.

Barrientos Grandón, J., "El 'mos italicus' en un jurista indiano. Francesco Carrasco del Saz (15?-1625)”, Ius fugit. Revista interdisciplinar de estudios históricojurídicos, 2, 1993, 43-61.

Benvenuto Straccha. Ex Antiquitate renascor, Atti del Convegno, Ancona, 22 de febrero de 2013, Ancona, Gabbiano, 2014.

Bravo Lira, B., "El derecho común en ultramar. Autores y obras jurídicas de la época del Barroco en Hispanoamérica", en Ius Commune. Zeitschrift für Europäische Rechtsgeschichte, xv, 1988, 1-42.

Bravo LiRA, B., "El derecho indiano después de la independencia en América Española: legislación y doctrina jurídica", Historia, 19, 1984, 5-52.

Bravo LiRA, B., "El derecho indiano y sus raíces europeas: derecho común y propio de Castilla", Anuario de Historia del Derecho Español, LVIII, 1988, 5-80.

Bravo LiRA, B., “'Odia restringi'. Forma y destino de una regla del derecho en Europa e Iberoamérica, durante la Edad Moderna", Ius Commune. Zeitschift für Europäische Rechtsgeschichte, XIX, 1992, 81-93.

Casagrande, A., s.v. "Curia Philippica (Philippic Court) 1603”, en Dauchy, S., Martyn, G., Musson, A., PihlajamäKi, H. y Wijffels, A. (eds.), The Formation and Transmission of Western Legal Culture. 150 Books that Made the Law in the Age of Printing, Cham, Springer, 2016, 156-158.

Coronas, S. M., "Hevia Bolaños y la Curia Philippica”, Anuario de Historia del Derecho Español, LXXVII, 2007, 77-93.

Cruz Barney, O., La codificación en México: 1821-1917. Una aproximación, México, UNAM, 2004.

del Vas Mingo, M. M. y Luque Talaván, M., "La usura en la literatura jurídica indiana de los siglos XVI-XVII: la propuesta de Juan de Hevia Bolaños y sus fuentes”, en Morales Padrón, F. (coord.), XIII Coloquio de historia canario-ameri- 
cana. VIII Congreso Internacional de Historia de América (1998), Cabildo de Gran Canaria, 2000, 1086-1106.

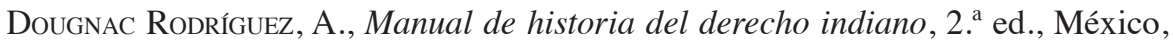
UNAM, 1998.

Estrada Michel, R., “Las relaciones entre México y el 'ius commune’ europeo. ¿Difusión, recepción, resistencia o mestizaje?”, en LANDI, A. (coord.), Esperienze giuridiche latino-americane e diritto comune romano-canonico. Saggi, Torino, Giappichelli, 2018, 35-89.

Franchi, L., Benvenuto Stracca, giureconsulto anconitano del secolo XVI. Note biobibliografiche, Roma 1988.

García-Gallo, A., "La ciencia jurídica en la formación del derecho hispanoamericano en los siglos XVI al XVIII", Anuario de Historia del Derecho Español, XLIV, 1974, 157-200.

García SÁnchez, J., “Juan de Hevia Bolaño: asturiano, autor de la 'Curia Filípica' y del 'Laberinto de mercaderes (anotaciones a una cuestión histórico-jurídica enigmática)"', Boletín del Real Instituto de Estudios Asturianos, año XLIX, 1995, 505-581.

García SÁnchez, J., “La 'laesio enormis': del rescripto de Diocleciano (C.4.44.2) al Codigo de Comercio hispano de 1829, pasando por Hevia Bolaño", Revue Internationale des droits de l'Antiquité, XLVIII, 2001, 91-129.

Garrido Arredondo, J., s.v. "Hevia Bolaño [o Bolaños], Juan de", Diccionario crítico de juristas españoles, portugueses y latinoamericanos (hispánicos, brasileños, quebequenses y restantes francófonos), I, Zaragoza-Barcelona, Univeridad de Murcia et al., 2005, 415.

GonZÁLEZ, M. DEL R., “Comercio y comerciantes en la legislación y la doctrina mexicanas del siglo XIX”, Anuario Mexicano de Historia del Derecho, II, 1990, 115-149.

GonZÁLEZ, M. DEL R., "El derecho indiano en el Diccionario de Escriche anotado por Rodríguez de San Miguel”, en Memoria del x Congreso del Instituto Internacional de Historia del Derecho Indiano, I, México, Eld-unAm, 1995, pp. 543-570. 
González, M. del R., "Estudio preliminar”, en Rodríguez de San Miguel, J. N., Escritos jurídicos (1839-1863). Antología, GonZÁLEZ, M. DEL (coord.), México, UNAM, 1992, 7-29.

GonzÁlez, M. Del R., Historia del derecho mexicano, México, unAm, 1983.

González, M. Del R., Historia del derecho mexicano, México, unAm, 1997.

GonzÁlez, M. Del R., "Introducción” a Rodríguez de SAn Miguel, J. N., Pandectas hispano-mexicanas, I, México, unAm, 1980 (reprod. de la ed. Méjico, 1852).

González Domínguez, M. Del R., “Juan N. Rodríguez de San Miguel jurista conservador mexicano”, en GonzÁlez Martín, N. (coord.), Estudios jurídicos en homenaje a Marta Morineau, I, Derecho romano. Historia del derecho, México, UNAM, 2006, 233-249.

GuZmán Brito, A., Historia de la codificación civil en Iberoamérica, Fundación Histórica Tavera, 2000.

LANDi, A., "Proiezioni ultramar del 'ius mercatorum' europeo. La definizione di fallito nel 'Labyrintho de commercio' di Juan de Hevia Bolaños”, en Petrucci, A. (coord.), I rapporti fiduciari: temi e problemi, en proceso de impresión.

LANDI, A., “'Unum et idem Regnum'. L'unione del Nuovo Mondo alla corona di Castiglia nella riflessione di Juan de Solórzano y Pereira", Quaderni fiorentini per la storia del pensiero giuridico moderno, XLI, 2012, 137-171, ahora en ID., Storia giuridica per futuri giuristi. Temi e questioni, Torino, Giappichelli, 2015, 99-132.

LaTINI, C., Il privilegio dell'immunità. Diritto d'asilo e giurisdizione nell'ordine giuridico dell'età moderna, Milano, Giuffrè, 2002.

LATTES, A., "Stracca giureconsulto", Rivista di diritto commerciale, VII, 1909, 624 ss.

LiRA, A., "Derecho e historia”, en Historia del derecho, ¿para qué?, Valencia, Tirant lo Blanch, 2020, 57-69.

Lohmann Villena, G., "En torno de Juan de Hevia Bolaño. La incógnita de su personalidad y los enigmas de sus libros", Anuario de Historia del Derecho Español, XXXI, 1961, 121-161. 
Lohmann Villena, G., “Juan de Hevia Bolaño: nuevos datos y nuevas disquisiciones”, Histórica, XVIII, n. . 2, 1994, 317-333.

Luque Talaván, M., Un universo de opiniones. La literatura jurídica indiana, Madrid, Consejo Superior de Investigaciones Científicas, 2003.

Malagón-Barceló, J., La literatura jurídica española del Siglo de Oro en la Nueva España, México, unAM, 1959.

Marina Martín, J., "Don Joaquín Escriche y Martín y sus obras”, Anuario de Derecho Aragonés, vi, 1951-52, 63-75.

Martínez Neira, M., "Lecturas antiguas y lecturas ilustradas. Una aproximación a los primeros manuales jurídicos", Cuadernos del Instituto Antonio de Nebrija, I, 1998, 143-209.

Migliorino, F., Fama e infamia. Problemi della società medievale nel pensiero giuridico nei secoli XII e XIII, Catania, Giannotta, 1985.

Morineau, M., "Dos juristas mexicanos del siglo xix: Antonio Florentino Mercado versus Juan Rodríguez de San Miguel”, Anuario Mexicano de Historia del Derecho, IX, 1997, 179-191.

Morles Hernández, A., Curso de derecho mercantil, i, Introducción. La empresa. El empresario, Caracas, Universidad Católica Andrés Bello, 2007.

Muñoz Planas, J. M., "Defensa y elogio de Juan de Hevia Bolaños: primer mercantilista español”, Revista de Derecho Mercantil, 2001, n. ${ }^{\circ}$ 241, 1109-1188.

Nuzzo, G., "Le conseguenze personali del fallimento dalla 'morte civile' alla politica della seconda opportunità”, en LANDi, A. y Petrucci, A. (coords.), Pluralismo delle fonti e metamorfosi del diritto soggettivo nella storia della cultura giuridica, I, La prospettiva storica, Torino, Giappichelli, 2016, 215-235.

PAdOA Schioppa, A., "Codificazione e legislazione commercialistica in Francia (17781915)”, en ID., Saggi di storia del diritto commerciale, Milano, LED, 1992, 63-88.

Padoa Schioppa, A., "Napoleone e il 'Code de commerce"”, en ID., Saggi di storia del diritto commerciale, Milano, LED, 1992, 89-112.

Pecorella, C. y Gualazzini, U., s.v. "Fallimento (premessa storica)", Enciclopedia del diritto, XVI, Milano, Giuffrè, 1967, 220-232. 
Peset, M., "Novísimo Sala mexicano o el final del viejo derecho hispano", en Bernal, B. (coord.), Memoria del IV Congreso de Historia del Derecho Mexicano (1986), II, México, UNAM, 1988, 895-913.

Petit, C., Historia del derecho mercantil, Madrid, Marcial Pons, 2016.

Piergiovanni, V., s.v. "Stracca Benvenuto", en Dizionario biografico dei giuristi italiani, Birocchi, I., Cortese, E., Mattone, A. y Miletti, M. N. (dirs.), i, Bologna, Il Mulino, 2013, 1920-1922.

Portalés Trueba, C., Derecho mercantil mexicano, i, Nociones básicas y generales, Ciudad Juárez, Universidad Autónoma de Ciudad Juárez, 2012.

Rocco, A., Il concordato nel fallimento e prima del fallimento, Torino, Fratelli Bocca editori, 1902.

Santarelli, U., Mercanti e società tra mercanti, 3. a ed., Torino, Giappichelli, 1998.

Santarelli, U., Per la storia del fallimento nelle legislazioni italiane dell'età intermedia, Padova, Cedam, 1964.

SBriccoli, M., L'interpretazione dello statuto. Contributo allo studio della funzione dei giuristi nell'età comunale, Milano, Giuffrè, 1969.

Scherner, K. O., "Die Wissenschaft des Handelsrechts", en Coing, H. (ed.), Handbuch der Quellen und Literatur der neuren europäischen Privatrechtsgeschichte, II/1, München, C.H. Beck Verlag, 1977, 797-997.

ScIumè, A., Ricerche sul fallimento nel diritto moderno, I, Il momento settecentesco, Milano, Giuffrè, 1985.

Speciale, G., Fallimento tra Dolo e Sfortuna. L'azione revocatoria e il diritto d'asilo nei secoli XVI-XVIII, Roma, Il Cigno Galileo Galilei, 1996.

Tau Anzoátegui, V., El jurista en el Nuevo Mundo. Pensamiento. Doctrina. Mentalidad, Frankfurt am Main, Max Planck Institut for European Legal History, 2016.

TeTI, R., Un diritto per gli imprenditori. Il diritto commerciale dalle codificazioni ottocentesche al codice civile del 1942, Roma, Donzelli, 2018.

Tomás y Valiente, T., Manual de historia del derecho español, 4. ${ }^{\text {a }}$ ed., Madrid, Tecnos, 2013. 